\title{
ARTES DE MUSICAR E DE IMPROVISAR NA CULTURA POPULAR
}

\author{
JOSÉ MACHADO PAIS \\ Investigador Coordenador do Instituto de Ciências Sociais da Universidade de Lisboa \\ e Professor convidado do Departamento de Sociologia do Instituto Universitário de \\ Lisboa - Portugal \\ http://jwww.jose-machado-pais.net
}

\begin{abstract}
RESUMO
O artigo explora bases de sustentabilidade do valor patrimonial das chamadas culturas marginais, tomando como referente empírico as artes de musicar e de improvisar. Aos preconceitos que associam a cultura popular à frivolidade se contrapõem evidências da sua criatividade. Para isso, comparam-se tendências e influências musicais de um e outro lado do Atlântico (Portugal e Brasil), na base de uma matriz partilhada de repentes e improvisações. Os exemplos do fado e do samba são usados para ilustrar as variações simbólicas, no decurso do tempo, das produções culturais: dos antros de marginalidade podem emergir ícones de nacionalidade. Em seguida, em um estudo de caso envolvendo jovens portugueses afrodescendentes, sem motivação extrínseca ou intrínseca para as aprendizagens do ensino formal, mostram-se reais possibilidades de emancipação através da música e da dança. Finalmente, equaciona-se a possibilidade de a educação, dada a sua aposta no conhecimento, poder constituir uma importante plataforma de reconhecimento do valor patrimonial das culturas populares.
\end{abstract}

CULTURA POPULAR - PORTUGAL - BRASIL - CRIATIVIDADE

\section{ABSTRACT}

THE ARTS OF COMPOSITION AND IMPROVISATION IN POPULAR CULTURE. This article explores the bases of sustainability of the patrimonial value of the so-called marginal cultures, taking the arts of composition and improvisation as its empirical referent. The prejudices associating popular culture to shallowness are opposed by the evidences of its creativity. Thus, the musical trends and influences on both sides of the Atlantic (Portugal and Brazil) are compared based on a shared matrix of repente melodies and improvisations. The examples of fado and samba are used to illustrate the symbolic variations of cultural production throughout the time: Nationality icons may emerge from dens of marginality. Subsequently, in a case study involving young Portuguese Afro-Descendants who have no extrinsic or intrinsic motivation to take part in formal school learning, real possibilities of emancipation are shown in music and dance. Finally, the article contemplates the possibility of education, given its bet on knowledge, being able to develop an important platform to acknowledge the heritage value of popular culture.

POPULAR CULTURE - PORTUGAL - BRASIL - CRIATIVITY 
A música popular constitui um campo privilegiado para a análise dos imaginários sociais. É certo que uma boa parte da enxurrada de música mais popularesca - "pimba" como é designada em Portugal ou "brega" como é conhecida no Brasil - é de qualidade duvidosa. Mesmo nesse caso, não deixam de ser sociologicamente relevantes os processos de estandardização que levam a indústria discográfica à conquista de amplos segmentos de um público mais vulnerável ao fenômeno da vedetização da música de baixa qualidade. De todo modo, seria um equívoco analisar a cultura popular somente pelo lado da recepção onde, particularmente no caso da indústria discográfica, mais se fazem sentir as manipulações dos circuitos de difusão comercial, sob os auspícios de uma lógica de mercado. O presente artigo centra-se, contudo, numa problematização diferente ao explorar as bases de sustentabilidade do valor patrimonial das chamadas culturas marginais, tomando como referente empírico as artes de musicar e de improvisar.

$\mathrm{Na}$ primeira parte do artigo, aos preconceitos que associam a cultura popular à frivolidade se contrapõem evidências da sua criatividade. Esta passa despercebida, por exemplo, aos eruditos que torcem o nariz ou fazem ouvidos moucos às expressividades musicais da cultura popular. Nesse campo, teremos oportunidade de comparar tendências e influências musicais de um e outro lado do Atlântico (Portugal e Brasil), na base de uma matriz partilhada em repentes e improvisações. Os exemplos do fado e do samba são usados para mostrar as variações simbólicas das produções culturais, ao se constatar que dos antros de marginalidade podem emergir ícones de nacionalidade.

$\mathrm{Na}$ segunda parte, em um estudo de caso envolvendo jovens afrodescendentes que, em Portugal, são apelidados de "desenquadrados" ou "problemáticos", sugerem-se reais possibilidades de emancipação através da música e da dança. Sem motivação extrínseca ou intrínseca para as aprendizagens do ensino formal, esses jovens dão mostras de uma notável capacidade criativa - tendo como suporte ágeis recursos de improvisação - quer no âmbito das suas subculturas de rua (associadas ao hip hop), quer quando, num projeto de intervenção comunitária (Batoto Yetu), se envolvem em danças tradicionais que se reclamam de heranças africanas. Falar de heranças culturais implica falar de conservação e reprodução, mas não impede de pesquisar os enclausuramentos a que podem dar lugar. Pretexto para avançarmos com a ideia de que as identidades não são regidas pela inevitabilidade da rigidez. 
As conclusões apontam as culturas marginais como um campo de criatividade e de improvisos onde se jogam diferenças e influências num rol variado de interações e hibridações, ao mesmo tempo em que se questionam os reducionismos que entravam a partilha de tradições e saberes culturais. A educação, por apostar no conhecimento, pode constituir uma importante plataforma de reconhecimento do valor patrimonial das culturas populares.

\section{OUVIDOS MOUCOS E NARIZES TORCIDOS}

Não sabemos se na música temos a origem da linguagem falada, como pretendia Darwin, ou se, ao contrário, ela tem a sua base na linguagem falada, como reivindicava Simmel (2003), na sua primeira tese de doutoramento, apresentada em I 88 I, sobre o canto tirolês primitivo. Mas quando, numa bela tarde, tomando um pouco de sol no Farol da Barra, em Salvador da Bahia, ouvi os pregões de um velho vendedor de queijo, sacudi os ombros, num gesto de desapego (que importa?) ao contencioso das origens. $O$ importante é não fazer ouvidos moucos à realidade que nos desperta os sentidos'. Só as oreIhas ouvidoras se podem tornar pensadoras (Schafer, 1992). O escutar é uma forma de perscrutar a realidade. Através da entoação do falar descobre-se a musicalidade da oralidade popular. É o que acontece, de forma muito evidente, com os pregões. $\bigcirc$ vendedor de queijos cantarolava: "O queijão chegou/ É só alegria/Vamos comer queijão/ No Farol da Barra da Bahia". Fazendo uma paragem na sua caminhada pela areia da praia, aparentemente para ajeitar a cesta à cabeça, continuou: "Tá beleza galera/ Solte o visual/ $\bigcirc$ meu queijão/ Não faz nada mal".

Aproximei-me do vendedor de queijo, dizendo-lhe do meu encanto pelo seu pregão, do mesmo modo que me fascinavam todos os ícones da baianidade: orixás, berimbaus, terreiros, lambretas e caldinho picante do Mercado Central, descontando os efeitos resultantes da sua desprevenida ingestão. Pena que o tempo fazia caretas, o sol brincava de esconder com acinzentadas nuvens. Quando questionei o velho baiano sobre se acaso iria chover, de imediato improvisou: "Galera, galera/ O tempo nublou/ O sol chegou/ É sol de Verão/

I. Desse modo James (1988) e Schutz (1964) definiam a realidade: como um universo de estímulos que nos despertam a atenção. 
De festa e alegria/ Olha o queijão/ Queijão da Bahia". Continuamos a conversar até que o amável vendedor ambulante foi cuidar da vida; ergueu a cesta do queijo à cabeça e, num repente, apregoou: "Eu asso um, eu asso dois, eu asso três/ A galera pede mais uma vez/ Pode pedir, português!"

Os eruditos torcem o nariz às expressividades musicais de cunho popular, qualificando de vulgaridade tudo o que sai fora dos cânones mais ortodoxos: da simples canção assobiada (tida como uma concessão à natureza animal) à dança folclórica (olhada como expressão da banalidade). No entanto, na cultura popular, as artes de improvisar estão bem presentes nas artes de musicar. Os pregões, com suas entoações melódicas, despertam-nos para essa mesma realidade, não obstante a recusa em ver o que ouvimos. Por isso, os vendedores que recorrem ao pregão fazem-nos sucessivos apelos para vermos o que apregoam. Os ouvidos moucos produzem um efeito de cegueira. Em Lisboa de outros tempos ouvia-se: "Olha a sardinha, vivinha da costa!"; "Olha a laranja, é da Bahia!"; "Olha o gelado, fruta ou chocolate!"... E no Recife apregoava-se: "Olha o amendoim, amendoim torradinho!"; "Pirulito, olha o pirulito!"; Caranguejo, olha o caranguejo!”...

Há, indiscutivelmente, uma arte nestas "performances comunicacionais" de expressão popular, que vão dos pregões aos improvisos e repentes, em forma cantada ou escrita, como acontece na literatura de cordel². A "globalização cronotópica” - isto é, não apenas a que atravessa as fronteiras espaciais mas também a que galga os marcos temporais - fez renascer o interesse por essas formas populares, originando múltiplas apropriações da chamada tradição. Em São Paulo, Rio e Brasília, a viola caipira travestiu-se de modernidade, apresentando-se como uma "viola turbinada" ou "viola groove". Os grupos na vanguarda deste movimento - Matuto Moderno, Mercado de Peixe ou Dotô Jeka - reclamando-se de um estilo "pós-caipira", exploram antigos ritmos como o cateretê ou o cararu, incorporando, em suas músicas, influências tipicamente urbanas, como assinala um músico: "A nossa viola soa de forma diferente. A

2. Mais vincada na literatura de cordel nordestina do que na portuguesa, onde a criatividade popular convivia com a poesia erudita (Abreu, 1999). Menção para o acervo reunido na Fundação Casa Rui Barbosa, no Rio de Janeiro. Em Portugal, a literatura de cordel tem merecido atenção por parte do Centro de Tradições Populares Portuguesas Prof. Manuel Viegas Guerreiro, na Faculdade de Letras da Universidade de Lisboa. Veja-se ainda Saraiva (2006). 
gente toca e ao mesmo tempo escuta tiros, freadas de carros, barulho de obras. Não é como no ambiente rural do antigamente" (Menocchi, 2003).

As artes de improvisar, tão características do repente, estão manifestamente presentes em muitos grupos atuais de música eletrônica. Grandmaster Flash, um dos mais talentosos discípulos do DJ Jamaicano, tinha o costume de desafiar o público a fazer improvisações, uma espécie de "repente-eletrônico", como também é designado o rap (Vianna, 1988, p.21). O fazer espontâneo, tão próprio dos repentistas nordestinos, vamos encontrá-lo, de fato, entre os jovens rap. Aliás, alguns músicos do rap brasileiro reivindicam essas influências. Assim acontece com Thaíde \& DJ Hum: "É o rap embolada/ É o rap e o repente rebentando na quebrada/ [...] Veja aí, meu povo, vem do mesmo ovo/ O rap e o repente, o neto e o avô/ [...] É o rap embolaaaada..."3

Outros jovens músicos procuram trânsitos entre o rap e o samba, principalmente o samba mais popular, o chamado "samba de quintal" ou de "partido alto". É o caso de Marcelo D2 quando, "À procura da batida feliz", assevera: "Busco na raiz e lá tá o que sempre quis/ não é saco de dinheiro que me deixa feliz". É a "batida" que o anima, "a força do rap", o "MC que é partideiro", o "bumbo que vira scracth". Marcelo acentua, naturalmente, descontinuidades entre o presente e o passado quando em Maldição do samba constata que, atualmente, "a percussão é eletrônica", "o coco é enlatado", "a banana é com chiclete"... e até "a favela aparece na Internet". Mas as artes de improvisar, essas persistem: "Declaro meu respeito a todos os rimadores/ Partidários repentistas e claro os versadores/ Porque quem versa não fica de conversa/ E se tem pressa rima melhor porque se estressa".

A criatividade irrompe frequentemente nas margens da sociedade estabelecida. Poderíamos dar como exemplos dois ícones das identidades lusa e brasileira: o fado e o e o samba. $\bigcirc$ fado apegou-se aos botecos mais populares da cidade de Lisboa enquanto que o samba foi um produto da senzala, para logo depois subir aos morros das favelas. Sociabilidades de taberna ou botequim viajaram também para o Brasil, onde se instituíram em coretos, designação dada a reuniões de amigos, bem regadas a vinho e a canto: "Oia como bebe / Esse povo do Brasi / Enxuga um garafom / Mai depressa q'um

3. CD de Thaíde \& DJ Hum, Assim caminha a humanidade, extrato da música "Desafio no rap embolada" (letra de Thaíde, Nelson Triunfo e Chico César; música de DJ Hum). 
funi" (Cascudo, 1999, p. 130). A dança estava muito associada à bebida. A mesma designação - "abrideira" - aplicava-se tanto à primeira dança quanto à primeira bebida. Nas baiucas de Lisboa como nas do Rio de Janeiro, Salvador ou Recife encontrávamos a dança do fandango, mesmo quando travestida de quadrilha. O padre Lopes Gama ( 79 | - | 852), em Carapuceiro, considerado um dos mais importantes jornais críticos de costumes da primeira metade do século XIX no Brasil, publicado no Recife de 1832 a 1842, testemunhava num exemplar de 1842: "Nas baiúcas mais nojentas/ Onde a gente mal se vê/ Já se escuta a rabequinha/ Já se sabe o balancê."

Nos botecos de Lisboa e arrabaldes o fandango cruzou-se com o lundum (também chamado lundu) e o fado ${ }^{4}$, tal como no Brasil. Um viajante de passagem por Portugal no terceiro quartel do século XVIII ( I772- |773) referia:

Foi em Mafra que tive o prazer de ver dançar o Fandango. Foi numa tasca. Foi dançado pelo dono da tasca com sua mulher, e com o acompanhamento duma guitarra. O tocador dedilhava várias cordas juntamente, a três tempos, e batia com a mão o compasso no corpo do instrumento. (Branco, 1879, p.264)

Depois de sublinhar que viu o fandango em dança de pares, continuou: "Os dançantes estão num movimento geral com o corpo, e todos os membros, algumas vezes até indecentemente, marcam o compasso com o pé e com castanholas. Havendo falta deste instrumento, marca-se a cadência com estalos de dedos. O homem tem o chapéu posto na cabeça, e dança com sua dama chegando-se e afastando-se, e fazendo numerosas reviravoltas e requebros" (Branco, 1879, p.266). Em 1848 há registro romanceado de um lundum dançado numa tasca da Madragoa, uma dessas "espeluncas que a título de uma licença para venderem vinho e água ardente", eram "o centro do mais torpe deboche" (Carvalho, 1849, p.3).

No Brasil, especialmente no Rio de Janeiro, muitas festanças reclamavam como atributo de qualidade, desde que não houvesse mortes, as "turras" e os "banzés". Em Recife da primeira metade do século XIX, os bailes de arromba tinham a designação de "facões". Os mais modestos eram conhecidos por "ca-

4. A triangulação entre fandango, lundu e fado é também proposta por Laplantine (2000, p.25-35). 
nivetes". Em ambos encontrávamos o lundum (Cascudo, 1999, p.38I) que, não por acaso, começou a ganhar conotações de "sacanagem" no linguajar popular ("por detrás do meu cu não quero lundu"). Na primeira metade do século XVIII havia batidas policiais em casas onde se dançava o lundu (Tinhorão, 1988, p.39). Em Lisboa, entre os fadistas, encontravam-se audazes jogadores do pau que, naturalmente, originavam muitas mortes "a paulada" (Pais, 2008). Da boemia lisboeta faziam parte os fadistas e todos os amantes do fado: as mulheres do dito (prostitutas), marialvas, toureiros, boleeiros, vagabundos, marinheiros etc. A arte de manipulação das cordas de guitarra estendia-se à ligeireza dos "golpes de navalha". A navalha era uma amante predileta do fadista. Quando faltava a navalha, os golpes eram a paulada ou a pezada. As próprias fadistas, prostitutas, manejavam a navalha com mestria. A "Barbuda", mãe da Severa (a mais idolatrada fadista do século XIX), era conhecida por ser uma mulher de "faca na liga, cabelinho na venta e língua de prata". A taberna impunha-se pelo vinho, petisqueiras, chinfrim.

Nesses cenários intimidadores há quem tenha dificuldades em reconhecer espaço para a criatividade popular. No entanto, o fado e o samba - ícones emblemáticos das identidades lusa e brasileira - acolheram-se nesses antros de marginalidade. De fato, das margens da sociedade estabelecida irrompe a improvisação, embora a criatividade surja, recorrentemente, num estuário em que deságuam saberes, experiências e tradições que se vão compartilhando e amalgamando. Aliás, os trânsitos culturais entre Portugal e Brasil são evidentes, sem esquecer outras marcantes influências, como as africanas. Nos cantos e cantorias, de um e outro lado do Atlântico, predominam os desafios, os improvisos, as pelejas, as disputas (Ornellas, 1999, p. 196). A improvisação acontece nos cantos ao desafio, nas desgarradas, nas chulas ou, como no caso da llha da Madeira, em despiques e charambas, especialmente durante as vindimas. Os cantares ao desafio que, tanto no nordeste brasileiro quanto nos Açores e Cabo Verde, levam o nome de "cantoria", encontram-se também em Portugal. No Alentejo, há o "cante ao baldão" (Barriga, 2003). No Minho, os cantos ao desafio lançavam-se de uma parcela rural para outra, por isso as mulheres tinham uma voz esganiçada, marca de garra e também da necessidade de se fazerem ouvir.

O "desafio" - entendido como disputa - inscreve-se numa longa tradição. No Brasil, já o encontramos no sistema de irmandades e confrarias, bem como 
nas corporações de músicos. Cada corporação tinha seu próprio estilo e o confronto ocorria em grandes festividades organizadas por governadores-gerais ou senados de câmara (Lange, 1996). Os descantes surgem, também, nas festas joaninas que os portugueses levaram para o Brasil. Em Memórias de um Sargento de Milícias, nos festejos de um batizado, no Brasil novecentista (o romance foi publicado em |854-1855), lá vemos, entre os convidados, os "d'além mar" tocando ao desafio e "os da terra" (brasileira) dançando o fado (Almeida, 1990). No Brasil, os repentistas nordestinos têm um notável sentido de improvisação. Eles encontram-se entre cantadores sertanejos, violeiros e tocadores de rabeca.

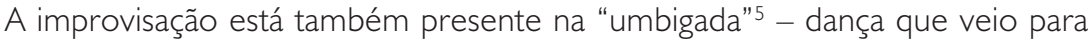
o Brasil com os escravos "bantos", muitos deles deslocados para a região de São Paulo onde trabalhavam na cultura da cana-de-açúcar e do café. Também chamado de "caiumba", o batuque da "umbigada" - que dá o nome à dança - é acompanhado de um canto, denominado "moda". Com refrões e versos improvisados, as modas aludem às vivências e acontecimentos da comunidade.

As improvisações musicais surgiam entre os escravos como brechas intersticiais lúdicas de uma vida de subjugações. O escravo Estrada de Ferro era famoso por imitar o silvo das locomotivas, executar polcas e valsas soprando no côncavo das mãos unidas, ou reproduzir sonoridades instrumentais batendo com os dedos nas bochechas (Moraes Filho, 1999, p.270-27I). Também nos festejos de bumba-meu-boi a escolha de algumas personagens era feita em função da capacidade de improvisação, e por isso se escolhiam mulatos ágeis de inteligência, capazes de divertir o público com suas anedotas e arremedos satíricos. A improvisação e os desafios marcam ainda presença nas "emboladas de coco", nomeadamente no "coco de desafio" (em sextilhas).

Também nas historietas de cordel há um forte sentido de improvisação. Sabe-se que a "literatura de folhetos", eventualmente herdeira da tradição das cantorias e histórias do romanceiro português, tem uma forte presença no nordeste brasileiro, desde finais do século XIX. Sabe-se que essa literatu-

5. Meu primeiro contato com a umbigada deu-se em São Paulo, em 2003. Além de ter participado numa dança, tive oportunidade de assistir ao documentário No repique do tambu, de Paulo Dias e Rubens Xavier, produzido pela Associação Cultural Cachuêra em parceria com a Fundação Padre Anchieta. $\bigcirc$ "tambu" é um tambor escavado num tronco. Há um outro tambor, denominado de "quinjengue", de som mais agudo, que dialoga com o tambu, além dos "guaiás", chocalhos de metal em forma de dois cones unidos pelas bases. 
ra - de "menoridade" considerada - sempre acolheu narrativas cantadas em versos metrificados, expressão de experiências rememoradas. Algumas dessas artes de improvisar surgiam no cenário dos terreiros de casa-grande, onde a poesia e o ritmo animavam os serões dos africanos escravizados. Antonieta Antonacci (2002, p. I 45- I 80) lança uma série de hipóteses bem interessantes sobre o processo de "mestiçagens culturais" que tomam a expressividade oral, na forma de "memória cantada", como veículo de afirmação identitária. Mencionando a terceira edição de Cantadores, de Leonardo Mota (1960), Antonieta Antonnaci dá destaque à apresentação que Câmara Cascudo faz dessa edição, particularmente quando sugere que "viver de cantoria era subalternidade e opróbrio"... ocupação de negros, escravos, batedores e pandeiros. E reforçando o apego dos africanos ao repente nordestino, aponta Gilberto Freyre que, em Casa-grande \& senzala, de 1933, já aludia às transformações que o romanceiro português experimentara no nordeste brasileiro, em suas interações com tradições africanas. Sustenta Freyre que:

As histórias portuguesas sofreram no Brasil consideráveis modificações na boca das negras velhas ou amas de leite. Foram as negras que se tornaram entre nós as grandes contadoras de histórias [...]. Há o akpalô fazedor de alô ou conto; e há o arokin, que é o narrador das crónicas do passado. O akpalô é uma instituição africana que floresceu no Brasil na pessoa de negras velhas que só faziam contar histórias. Negras que andavam de engenho em engenho contando histórias às outras pretas, amas dos meninos brancos. (1995, p.330-331)

De raiz genuinamente popular, principalmente no caso brasileiro, a literatura de cordel era largamente consumida por camadas populares: em feiras, romarias e na própria cidade. Não por acaso, era também designada de "literatura de cego", dado ser habitualmente apregoada por cegos.

\section{MÚSICA, DANÇA E EMANCIPAÇÃO: UM ESTUDO DE CASO (BATOTO YETU)}

Se uma viagem pela história do Brasil e de Portugal nos mostram que os repentes e improvisos sempre estiveram presentes na cultura popular, discutirei agora o papel das artes de musicar e de improvisar nas aprendizagens não- 
formais adquiridas no âmbito de projetos de intervenção comunitária como forma de combate à exclusão social. Em Portugal acompanhei alguns desses projetos envolvendo jovens que, de início, não se encontram nem extrínseca nem intrinsecamente motivados para a aprendizagem formal ${ }^{6}$. Aliás, essa aprendizagem aparece reconhecidamente associada a motivações de natureza extrínseca pois, salvo exceções, apoia-se mais em incentivos externos ou ameaças e sanções negativas do que no prazer da aprendizagem, independentemente das recompensas externas (Bois-Reymond, 1999, p.21-45). Tomarei agora um desses projetos - Batoto Yetu - como estudo de caso para algumas reflexões sobre a contribuição das artes como forma de emancipação.

Em suaíli, batoto yetu significa "nossas crianças"7. O projeto envolve cerca de meia centena de crianças e jovens com idades que não ultrapassam os 25 anos, de ascendência africana, majoritariamente de Cabo Verde. É convicção dos responsáveis pelo projeto que, por meio das danças, canções e lendas, os jovens "redescobrem as suas raízes", adquirindo autoestima, perseverança, disciplina e sentido de responsabilidade. Uma das condições básicas para que os jovens possam fazer parte da família Batoto Yetu é ter bom aproveitamento escolar. Surpreendentemente, alguns deles atingiram o nível universitário. Outra condição é o gosto e o jeito para a dança. Os jovens da Batoto Yetu abraçam o mundo da dança com grande paixão. Alguns acalentam o sonho de uma carreira artística. Como o sucesso na escola formal é condição necessária para continuarem na Batoto Yetu, apostam abnegadamente no sucesso escolar, apesar de a motivação ser de natureza extrínseca.

O trabalho de campo contemplou a realização de entrevistas com os jovens (individuais e em grupo), ao lado de outros registros etnográficos (acompanhamento de atividades e diários de campo $)^{8}$ e de entrevistas com agentes

6. Os projetos foram acompanhados no âmbito de um projecto internacional de pesquisa: Youth Policy and Participation: Potentials of Participation and Informal Learning in Young People's Transitions to the Labour Market. A Comparative Analysis in ten European Regions, apoiado pela Comunidade Europeia (Programa Improving the Socio-Economic Knowledge Base).

7. A Batoto Yetu implantou-se em Portugal, em 1996, embora a iniciativa tenha surgido antes, em 1990, no Harlem (Nova lorque), sob o impulso de Júlio Leitão, coreógrafo angolano, imigrado nos Estados Unidos. O músico António Laginha participou também na fase de arranque do projeto, tendo-me fornecido indicações preciosas sobre a história dele.

8. O trabalho de campo iniciou-se em 200 I intensificando-se nos três anos seguintes. Continuo acompanhando o projeto, embora menos intensivamente. 
envolvidos, direta ou indiretamente, com os projetos. Procedi à gravação das entrevistas mais diretivas (em cassete e, quando em grupo, em vídeo), tendo realizado documentários sobre as suas atividades (culturais e de aprendizagem). Comecei por assistir aos ensaios da Batoto Yetu fazendo observação direta. A maior parte dos dançarinos é do sexo feminino enquanto que os rapazes monopolizam a instrumentação musical. Em momentos de maior descontração e brincadeira ocorre uma inversão de papéis: as moças vão para a percussão e os rapazes dançam. Surpreendeu-me a forma aparentemente caótica como decorriam os ensaios. Começavam com exercícios de aquecimento, com alguém do grupo assumindo uma posição de liderança que, logo depois, passava a ser exercida por outros. Ou seja, deparei-me com uma liderança rotativa, propícia a uma democratização de funções e a um reforço do trabalho de equipe. Então descobri que o caos tinha uma ordem. Estava perante um caos criativo que logo me fez lembrar o movimento novaiorquino Grand Union, surgido nos anos 1960 e 1970 e robustecido por coreógrafos como Twyla Tharp. Seu trabalho, como se sabe, era construído em torno dos movimentos e padrões da não-dança ou, como foi posteriormente denominada, da "antidança". O aleatório e o acaso eram com frequência incorporados à coreografia, de modo que os bailarinos não sabiam, no início, como evoluiria a dança, criando-se oportunidades para as artes de improvisar. A música era recorrentemente interrompida para ser substituída por silêncio ou ruídos aleatórios de rua. Os acontecimentos exógenos desempenhavam um papel central na cena e era frequente a participação de grafiters de rua que coloriam paredes em contraponto com os bailarinos; outras vezes, os bailarinos ocupavam diretamente as ruas, pontes e telhados das casas, interagindo espontaneamente com os transeuntes (Berman, 1986, p.302).

Nos ensaios da Batoto Yetu observei que os jovens exercem um poder de liderança repartida. As formalidades ou hierarquias subordinam-se à construção coletiva, movida por um desejo de participação. Por outro lado, não há uma obrigatoriedade de aprendizagem. Todos aprendem por gosto, voluntariamente. Se no decurso dos ensaios ou das atuações alguém ganha evidência, parece que todos se deixam arrastar por uma energia coletiva e fluida. Os jovens aprendem também a conhecer os seus próprios limites e a lidar com a frustração, sempre que os movimentos de dança não saem bem. Os ensaios têm uma duração de cerca de três horas, com um intervalo para 
lanche com sanduíches e laranjada. Depois do lanche, comido sofregamente, os jovens entregam-se às performances com mais exuberância, pois é hora de aprimorarem passos de dança ensaiados anteriormente. Os corpos, suados, movimentam-se harmoniosamente, em sincronia com o batuque dos tambores. Ao som dos tambores e djambés, evocam-se "heranças culturais", arquitetadas na dança, em lances de corpo que dão corpo a laços identitários. Esse é um dos objetivos reclamados no ideário do projeto, o reconhecimento de uma identidade negada. As encenações dramáticas e ritualísticas criam um clima propício ao desprendimento dos constrangimentos quotidianos. No final de um dos ensaios, converso com alguns jovens dando-lhes conta da minha última viagem ao Brasil. Digo-Ihes que ao visitar uma loja de artigos de candomblé me encantei por um agogô que logo adquiri. Prometo-lhos que no próximo ensaio o trarei, certo de que vibrará muito mais nas suas mãos do que nas minhas. Seus olhos brilharam. E voltaram a brilhar quando, no ensaio seguinte, Ihes ofereci o agogô prometido. Fiquei impressionado com as sonoridades produzidas. Um deles exclamou: "Bué de power!".

Os jovens mais velhos socializam os mais novos na aprendizagem das batucadas. Reparo que todos vestem roupas muito práticas, predominando os jeans e as camisetas largas. Calçam tênis de marca. Provavelmente, a compra de grifes é um modo particular de afirmação simbólica de identidade. A questão de saber se os jovens afrodescendentes podem ou não afirmar sua identidade por intermédio das "marcas" permanece em aberto, apesar da associação, por exemplo, de Michael Jordan aos tênis Air Nike. Jordan é Air Nike e, nesse sentido, a ligação entre a marca de tênis e a estrela do basquete sugere muito mais que um produto personalizado. Sugere a transformação de Jordan num símbolo avidamente consumido pela mediação dos tênis e apesar do preço exorbitante destes. No entanto, não é certo que todas as ritualizações juvenis de "estilos de vida" tenham um significado político ou identitário. A força do mercado também atua na determinação dos hábitos de consumo.

Antes ou depois dos ensaios aproveito para saber um pouco mais da vida dos jovens da Batoto Yetu. Marília nasceu em Angola de onde veio aos 6 anos para viver com a avó paterna, num bairro degradado da Grande Lisboa. Sua mãe falecera e o pai fora preso por motivos políticos. Tem 5 irmãos "oficiais" e outros mais. Frequentou uma instituição de acolhimento de jovens "problemáticos". Marília conta-me histórias de "chincadas", merendas em bando de 
fruta roubada. "Chincar" é também a designação que se dá a quem consegue desarmar uma armadilha, extraindo a isca, sem ficar preso. A vida de muitos jovens de ascendência africana que vivem em Portugal (Gusmão, 2004) é, frequentemente, um exercício de chincada. Só com muita arte - "jogo de cintura", como se diz no Brasil - conseguem libertar-se das armadilhas com que, esperada ou inesperadamente, se confrontam. Prestes a terminar uma licenciatura em Gestão de Empresas, Marília apenas reprovou um ano escolar, por não ter conseguido conciliar os estudos com o trabalho, na área de marketing. Anteriormente trabalhara na Zara e num quiosque de rua ("horrível, tinha muito frio à noite"). Agora é monitora de dança, decidiu não acumular mais trabalhos para não prejudicar os estudos. Aliás, na Batoto Yetu, sustenta Marília, "quem não tem boas notas não pode viajar e eu gosto muito de viajar". Por isso, faz o possível por aguentar as aulas menos interessantes, e no limite da paciência desabafa para o seu diário: "Estou numa aula muito chata, já não consigo manter os olhos abertos. Estou a ter Direito do Trabalho, não sei como este professor fala tanto, tanto... que nem nota que estamos presentes [...]. Este professor e a professora de Análise de Dados conseguem pôr-me KO”.

Marilia olha o futuro com ilusão. Daqui a vinte anos ainda se imagina dançando na Batoto Yetu: "Acho que isto é lindo. Há pessoas que pensam que é só "tar" aqui a dançar [...] mas a dança é mais do que isso". Gostaria de exercer gestão de empresas, mas também seguir a carreira de dança, talvez na Inglaterra ou nos Estados Unidos, porque em Portugal é mais difícil. Fala com entusiasmo da possibilidade de levar a Batoto Yetu para Angola. Aí formariam uma "comunidade de cubatas" (casas de palhoça, comuns na África), dispostas em círculo, cada uma com sua função: uma cubata de artesanato, uma cubata de desporto, outra de trabalhos de oficina... e no centro um palco, para a dança. As cubatas incorporam a magia integradora do círculo. No centro do círculo o palco da dança, que tudo faz girar. $O$ ato criativo sempre apareceu associado a "conotações sociais, mágicas, religiosas, simbólicas" (Ostrower, 1983). Costumes ancestrais enfatizam o poder do centro que pode também ser ocupado por uma fogueira crepitando, em redor da qual se evocam os espíritos, ao som dos tambores e de cânticos que soam a uma religiosidade ancestral. Cânticos que ecoam num círculo de comunhão de corpos e fusão de sentimentos, arena de energias, foco de desejos. Marília entusiasma-se com essa magia, confessando ao seu diário: "Adoro ritmos africanos porque tam- 
bém já me correm nas veias. Os ritmos africanos transmitem a minha cultura, fazem-nos sentir os nossos antepassados, lembram-nos a nossa terra querida".

As lendas africanas, como é o caso da que relata o nascimento de Kamulango, cuja celebração é feita em espetáculos da Batoto Yetu, sugerem que os sons dos tambores viajam longe, tão longe que podem acordar o sol. E o sol chama as chuvas. E as chuvas formam caudais que se transformam em rios que regam a terra e alimentam os povos. A música tem esse poder mágico de evocar o passado, revigorar memórias, fortalecer identidades. Seja como for, a reivindicada ligação ao passado é artificial (Hobsbawn, Ranger, 1983), as "raízes" são reivindicadas e reelaboradas para legitimar o presente. Mesmo os provérbios podem ser reclamados como projeções do passado sobre o futuro, tendo como referência o presente. Há um ditado africano que os jovens da Batoto Yetu incorporaram como lema de vida: "Se podes andar também podes dançar, se podes falar também podes cantar; se existimos temos o dom de alcançar".

Apresento outro jovem, George, cuja trajetória de vida acompanhei de perto. Com ele me encontro, tomo contato com seus espaços de sociabilidade, conheço os seus pais, namorada e amigos de bairro, visito lugares que marcam presença nas suas memórias de infância, como a escola que frequentou ou a Pedreira dos Húngaros (em Lisboa), bairro conhecido pelo tráfico de droga e onde passou parte da sua infância. Num diário, que lhe pedi para escrever, desabafa:

Foi lá [Pedreira dos Húngaros] que aprendi muitas coisas que sei hoje e se calhar foi de lá ter morado é que penso como penso hoje que esta vida é fuck, quantos mais problemas temos mais aparecem, e queremos resolver cenas mas mais se complicam, muitas vezes fico sem forças mas temos de continuar nesta luta que é a vida.

George nasceu em Portugal, seus pais são de Cabo Verde (São Vicente). Entre os amigos é conhecido por Bjoy ("Ya, sou eu, Bjoy, mais conhecido por George; na mentira é ao contrário, 'tá-se bem'”). Chegou ao $8^{\circ}$ ano da escolaridade obrigatória, com três anos de reprovações. Abandonou a escola e ficou dois anos "sem fazer nada". Quando Ihe perguntei o que fazia durante o tempo em que dizia nada fazer respondeu-me que acompanhava alguns DJ's: 
"Trabalhava à noite nas discotecas, fazíamos uns trocos". Depois frequentou um curso de formação profissional, na área de informática: "É essencial, hoje tudo funciona à base de informática. Computador para aqui, computador para ali". Participou também num filme sobre gangues juvenis, Zona J: "Experiência interessantíssima. Era uma das coisas que gostava de fazer na vida, mas a vida às vezes não nos leva para esses caminhos". A mãe do George, receosa das más companhias que poderiam fazer o filho cair nas drogas e na delinquência, decide abandonar a Pedreira dos Húngaros e ir viver para Miratejo (em Almada, na margem sul do Tejo). Agora, quando George atravessa o rio, no Cacilheiro, reflete: "Ver Lisboa de um lado e Almada no outro faz-me pensar na vida, pensar em cenas, pensar se o mundo fosse meu o que faria para o mudar". No bairro onde agora vive fez teatro criativo: "Juntávamos bocados de peças de vários artistas e fazíamos outra peça. Fazíamos uma história dentro daquelas histórias todas". Tentou a vida na Inglaterra, onde tem um irmão. Passou dois meses lá, como segurança de uma empresa de ótica, mas regressou a Portugal e à Batoto Yetu: "Isto aqui é uma grande família, quando alguém se vai embora acaba sempre por voltar".

George me dá a oportunidade de conhecer os seus amigos (crew) e de tomar parte das suas conversas e sociabilidades. Todos estão ligados ao rap e ao hip hop. Nas letras que eles próprios improvisam há uma alusão permanente às suas reais condições de vida: "Eu não escolhi esta minha vida; tento arranjar uma saída; para não acabar com ela fodida". Inventario expressões que usam frequentemente e que remetem ao seu mundo de cotidianeidade (Pais, 2003): cabelos (nada); tarla (idiota); bacan (básico); babi (polícia, porcos, chulos, bófias); ioxi (haxe); chariba (idem); stala (efeito de droga, moca); aparar (dormir); calminho (não está acontecendo nada, sem problemas); straiht (tudo bem); smooth (sem problemas, ou atritos); ganda tanga (mentira); gasosa (mentiroso); tripar, flirtar (passar-se); fussil (isqueiro); lume (tiro, balázio); skills, (conhecimentos, experiência); clean (sem drogas); guita ou cacau (dinheiro); movies (situações); bacano (amigo); motherfuckers (designação dada a gente de que não se gosta); tripar (ficar furioso); bazar (sair); pitar (comer pitéu); estar down (estar em baixo); bué de tempo (há muito tempo); stones (charros); cubico (casa); wathever (o que quer que seja); ficar um coche (ficar um bocado de tempo); life goes on (a vida segue em frente); peoples (pessoas); manbiti, cena (situação); liso (sem dinheiro). Também descubro que o léxico usado é 
uma forma de distinção, o mesmo se podendo dizer dos piercings e tatuagens: "Quero fazer uma tatuagem no braço mas não sei bem o quê, complicado, né?, penso num leão agressivo mas há muitos leões, quando lá for ao estúdio das tatuagens um gajo logo vê o que vai sair". Por vezes, a linguagem que usam reproduz expressões cunhadas por aqueles que os estigmatizam. Forma corrente de saudação é: "Como é que vais, ó preto?" Ao fim e ao cabo, todos aqueles que são objeto de preconceito são a "língua" em que são falados, as imagens em que são reconhecidos, a história que os faz lembrar os impasses do presente. Mas eles podem também ser a "língua" que questiona essas pressuposições, as imagens que se rebelam contra os estereótipos, a história de que não se podem alhear (Manguel, 2000, p.35).

A convite do George, visito a Associação Caboverdiana do Seixal e a escola de formação profissional que frequenta, em Cruz de Pau. Folheio seus trabalhos escolares. Alguns versam sobre Cabo Verde, terra de mornas, mazurcas, sambas. E lá vêm alusões às tabancas - cortejos artísticos e musicais que remontam ao período da escravatura. George conta que, durante esses festejos, os escravos tinham um dia de folga, em comemoração de Santa Cruz, no dia 3 de maio. Costumavam, então, organizar uma espécie de teatro de rua, em que a sociedade do poder - governantes e eclesiásticos - era caricaturada. George recorda os preparativos que agora se fazem da festa, as mulheres a baterem o pilão para a extração do farelo e do milho cotchi e a produção de xerém e cuscuz, tudo animado a batuque e grogue. George gosta de escrever sobre as mornas e a "sodade" dos caboverdianos espalhados pelo mundo, do destino de quem quer ficar e tem de partir; da coladeira e do funaná, canções de humor, alegria e sensualismo; do pilão da ilha do Fogo, nas noites que antecedem as festas da Bandeira, quando as mulheres pilam o milho para preparar o xerém, ao som de cantigas, do rufar de tambores e do matraquear de "tchabeta" na borda dos pilões; da "finaçon" que remonta à época da escravatura; das músicas importadas da Europa - mazurca, contradança, conto da divina - e das já faladas "tabancas", originárias da Ilha de Santiago, tocadas com búzios soprados, tambores e cornetas e em que as mulheres participam tocando percussão em panos, bolsas e garrafas de plástico.

A paixão com que George fala da sua terra sugere a existência de vínculos culturais que se manifestam em crenças, afetos, lealdades, apegos e adesões. Muitas pessoas têm paixão pela sua terra. Por que deveria ser diferente com 
o George? No entanto, a exaltação das origens culturais também não será alheia à situação de desconforto com que frequentemente se vê na sociedade portuguesa, embora também sinta orgulho de ser português, como qualquer jovem português que tem orgulho de ser transmontano, minhoto, algarvio ou açoriano. George é crítico em relação à sociedade que o rodeia: "Muitas vezes as portas que nos são dadas não abrem porque o sistema não quer que as portas estejam abertas". Da escola formal não guarda boas recordações, contrapondo-lhe as aprendizagens informais do dia-a-dia: "Ya! Muita coisa está mal na escola [...]. A vida é uma escola, todos os dias vamos aprendendo, todos os dias". É crítico também em relação à pedagogia do "despejar matéria":

A matéria tem de ser dada, de $\times$ a x; mas acho que os professores tinham de ter mais dinâmica, não chegar à aula e... de x a x; deviam entrar mais na onda dos alunos. Muitas vezes os professores não sabem dos problemas que os alunos passam. Deviam ser mais uma família. A escola é tipo uma segunda casa! Mas não é aquela coisa de "Ya! Vou para a escola com gosto"!... É mais: "Eh pá, lá tenho que me levantar para ir para a escola!". A maioria dos professores limita-se a despejar matéria. Quem passou, passou; quem não passou, lerpa.

Jovens como o George não se sentem bem na escola formal, pois ela privilegia uma temporalidade monocromática que enfatiza uma segmentação de tempos letivos que se justifica por si mesma ou pelo toque de uma campainha que encerra uma aula quando se discute algo interessante ou, mais frequentemente, quando a arrasta num tempo que nunca mais acaba. Em contrapartida, fora da escola predominam as temporalidades policromáticas que caracterizam as sociabilidades espontâneas, onde várias coisas acontecem ao mesmo tempo. É o que se passa quando George se encontra com a sua crew - Mira Squad constituída por várias bandas musicais: Guetto Bastard's, 3llegais, Swimmr's MC, Seringuetti e Kulture, seu grupo de percussão?. É nessas temporalidades policromáticas que as artes de improvisar se afirmam em toda a sua criatividade.

9. "O meu grupo chama-se Kulture, então eu pensei... não vou fazer uma cena vulgar, vou, ya, foi no quarto do Kiki que é o nosso guitarrista [...], sai à toa um som tipo reggae, eu fiz um bit box e disse, ya, isto encaixa. Daí nasceu Kulture". 
Nós temos aqueles estúdios de bairro; bandas de garagem; nós temos caixas de ritmos, fazemos samples de música: muda o baixo, bateria, mudamos tudo, fica só a melodia. Daí criamos o resto com o computador. Tentamos pôr um CD cá fora mas é difícil. Hip hop hoje é um mundo! Eu faço rap, rap de rua. Juntamo-nos dois ou três na rua, duas violas, eu faço de bateria (colocando a mão na boca e imitando um som de percussão). O rap trata daquilo que nós vivemos, daquilo que nós passamos, daquilo que nós sofremos.

George reivindica a possibilidade de uma "pedagogia da criatividade", semelhante à que é posta em jogo com os amigos: "Pego numa guitarra e faço coisas que me vêem à cabeça [...]. A people curte". $\bigcirc$ sentimento de reconhecimento ("a people curte") é importante para a autoestima, o que não acontece na sala de aula, quando as dificuldades de aprendizagem são rapidamente associadas ao estigma de "burrice": "Um gajo sente-se bem em cima do palco, com a people a bater palmas. Yá! Um gajo sente-se bem. Muito fixe! É autoestima!" A criatividade fomenta a participação pelo desenvolvimento de potencialidades que os jovens libertam quando, através das suas artes de musicar e improvisar, desafiam o desencanto da vida, guarida de um individualismo não solidário (Vilanova, 2000). A estética da música e da dança consolidam uma ética de vida que acentua o sentido da responsabilidade. $\bigcirc$ desejo de participação criativa por parte dos jovens é muitas vezes mal compreendido pelas autoridades:

Estamos lá sem fazer nada, depois aparece um com guitarra, põe-se a fazer bitch, depois aparecem mais dois, depois mais dois, os do túnel aparecem, depois já está bué de gente, aparece a PSP [Polícia de Segurança Pública] de Almada, como sempre, "Pá, têm que dispersar"... e vão logo uns para o Pragal [posto da polícia].

A intolerância, às vezes, esconde-se sob a máscara da tolerância. Esta não implica necessariamente a aceitação do outro, pode apenas ser uma maneira sutil de reafirmar sua exclusão (Mendus, 1989, p. 149-150): "Associam logo calças largas, chapéu virado para trás, com bandidos". No caso de a suspeita corresponder à realidade, ela acabará por refletir a coloração mental de 
algumas representações sociais que impendem sobre jovens só pelo fato de serem negros. Quando estão em grupo, os jovens afro-descendentes se veem olhados como mais suspeitos, como suspeitos são os lugares que frequentam ou os bairros onde vivem. Um deles lamentou-se:

E vêm: "lá [no bairro] tudo faz isto e acontece"... Não, eu não faço "isso e acontece" [...], eu posso estar nesse movie, eles pensam sempre assim "como estás aí enfiado nesse grupinho"... é o que eles pensam... "Tão ali os pretos"... Ainda sentimos na pele, às vezes. A coisa má é de sentir. Nós sentimos muitas coisas aqui em Portugal. Mas, pronto, vamos vivendo com isso, vamos aguentando, faz parte. Assim abrimos mais a pestana, ficamos mais a par das coisas.

A cultura hegemônica é uma cultura bem mais de exclusão do que de inclusão. Porém, a exclusão por razões étnicas pode originar formas reativas de inclusão, também por razões étnicas. Nessa medida, o "pertencimento étnico" é suscetível de ser instrumentalizado como fonte de referência simbólica, ao assegurar um sentimento de reconhecimento e identidade (Horowitz, 1985). Numa lógica semelhante, também se tem discutido a valorização das culturas marginais de modo a que possam ser reconhecidas. Esse é um dos desafios da Batoto Yetu: a potencialização da notável capacidade de improvisação e criatividade dos jovens que são olhados como marginais. Improvisam ao compor música ou ao dançar, mas também improvisam no palco da vida.

Se não tivéssemos sentido de improvisação... Eu já tive espetáculos em que arrebentavam as coisas. Uma vez, estávamos a representar os Lusíadas, era aquela cena do Cabo das Tormentas. E o pano do palco não caiu, a corda arrebentou-se e não desceu a tela... "Monstro! Monstro!" e o tonto monstro não aparecia. Foi aquela cena de improviso: "Então não apareces? Tens medo?". Havia milhares de pessoas a assistir à peça, e pensaram que tudo fazia parte do texto.

O que está em jogo é a sobrevivência em uma sociedade do desperdício. Para isso, é necessário ser "esperto", "ir à luta", "se virar". O espírito de improvisação é notório quando esses jovens utilizam o sampling, mistura de sons que pode passar pela técnica da pilhagem, sonic shop-lifting (Best, Kellner, 
200 I , p.20 I -224). Em relação à criatividade que é própria do hip hop (Fradique, 2002), um jovem me disse:

É tudo criado por nós. Tem tudo a ver com o graffiti, com o break dance, com o DJ [...]. Mensagens que as pessoas precisam de ouvir. Acho que é o que falta neste mundo [...]. Apesar de nós termos esta cor aqui (passa a mão pelo antebraço), não nos vamos deixar ficar por aqui, ficar por baixo. Vamo-nos pôr em bicos de pés, limpar o colarinho, levantar a cabeça e seguir em frente. Que foi o que a minha mãe me ensinou: "Pá, olha, não deixes que ninguém te pise! Ninguém come em cima da tua cabeça!" [batendo com a mão na cabeça] Ninguém come em cima da minha cabeça, então.

Idealmente, a arte surge para os jovens da Batoto Yetu, assim como para os jovens envolvidos no movimento hip hop, como um poder de emancipação, uma experiência criativa de afirmação. Não estamos perante ressurgimentos de identidades nativas, intemporais e imutáveis, mas, mais propriamente, perante usos lúdicos de recursos culturais que são valorizados como fazendo parte de uma "memória cultural". Em certa medida, está em jogo um resgate do passado que não pode deixar de ser interpretado como efeito de um desgaste do presente. Por essa razão, sustenta Hall (200 I), a etnicidade não passa por uma pretensa descoberta das raízes do passado, mas afirma-se numa busca de rotas do presente - em um "quem posso vir a ser", ao invés de um nostálgico "de onde venho". O batucar, o dançar e o cantar são instrumentos de uma figuração de vida feita de aquarelas de desejo, sem o que a vida permaneceria descolorida. Questão em aberto é a de saber se nessa experiência estética podemos encontrar fontes de inspiração de uma lógica que supere as vicissitudes de vida.

Por paradoxal que possa parecer, o sucesso da Batoto Yetu se assenta na capacidade do projeto galgar as fronteiras da etnicidade que parece enaltecer. Os jovens da Batoto Yetu possuem sua própria memória cultural (construída a partir das vicissitudes do presente), mas também sentem necessidade de irromper pelas estruturas da cultura dominante. Eles mobilizam-se para arranjar sponsors e espectáculos e ei-los invadindo os palcos consagrados da produção cultural (como o Centro Cultural de Belém ou o Teatro de São Carlos), ei-los aparecendo na televisão e ganhando concursos internacionais de expressão 
artística. Por outro lado, na filosofia do projeto da Batoto Yetu, tanto quanto nos foi dado a conhecer, o impulso à recriação das heranças culturais não significa o estabelecimento de células autárquicas. A valorização das aprendizagens informais também não implica uma renúncia ao ensino formal, do mesmo modo que a reivindicação de pedagogias orientadas para a criatividade não anula a necessidade de aprendizagens orientadas para a aquisição de outros acervos de conhecimento.

Seja como for, a partir da experiência da Batoto Yetu, podemos questionar a razão pela qual as artes ligadas às performances musicais e corporais estão tão ausentes da escola formal. Por que elas continuam sendo marginalizadas e consideradas matéria de categoria inferior? Se os jovens aderem tanto à música, por que a escola não a incorpora como eixo incentivador do conhecimento, o mesmo acontecendo com outros aspectos culturais ligados ao mundo fenomenológico dos jovens? Por que a matemática, através da análise combinatória, não é chamada, a esse propósito, a ilustrar os múltiplos arranjos de uma composição musical e vice-versa? Por que a geometria analítica não é chamada ao entendimento das configurações harmoniosas que os corpos produzem enquanto dançam e vice-versa? Por que a escola não potencializa a criatividade das culturas juvenis, tão frequentemente desvalorizadas?

\section{CONCLUSÕES}

O estudo de caso analisado sugere-nos que os pertencimentos étnicos podem ser usados para a imputação de estereótipos, mas também podem ser reivindicadas como refúgios culturais que se traduzem num reforço de discriminação (Rothschild, | 98I). Em ambos os casos - especialmente se conjugados - há riscos de uma absolutização étnica (Baumann, 1999). A dimensão étnica da identidade constitui-se frequentemente nesse lugar de refúgio contra um mundo hostil que provoca ameaças de desenraizamento e a própria negação da identidade (Nasch, 1989). Em contrapartida, a valorização das diferenças expressadas pela etnicização pode significar "incorporar os critérios de discriminação que estiveram na origem dessa mesma etnicização" (Pires, 2003, p.7). Como libertar as diferenças do espartilho da etnicização?

Um problema de muitas pesquisas que recorrem ao conceito de etnicidade é projetar nos objetos de estudo a rigidez semântica desse mesmo 
conceito, ao qual se subsumem tais objetos (Terrén, 2002, p.45-57). Desse modo, fazem sentido as críticas às concepções essencialistas das identidades que tomam as "culturas de origem", performatizadas em termos "caricaturais e folclorizantes", como um "todo integrado e homogêneo" (Machado, 1994, p. 120), estável e imutável. Esse essencialismo tende a ver os membros das minorias culturais como portadores de uma identidade homogênea. Trata-se de um "essencialismo epistemológico" que reifica as culturas como expressões fixas e mutuamente impermeáveis de identidade racial (Hall, 1992). Ou seja, há uma absolutização das identidades tributária de uma naturalização das culturas que lhe dão suporte, daí derivando um possível reforço das segregações sociais de base étnica ou cultural. O projeto acompanhado (Batoto Yetu), como muitos outros do gênero, parece operar, à primeira vista, numa base de "autorracialização" (Taguieff, 1988), ao reivindicar uma valorização das "raízes culturais" africanas. No entanto, entre os jovens negros que participam na Batoto Yetu há claras evidências de um desenclaustramento étnico. É certo que, através das suas danças, se geram identificações simbólicas que procuram revalorizar o que é frequentemente desvalorizado nos processos de discriminação quotidiana. No entanto, as memórias ficcionais de um "passado comum" são colocadas em cena a serviço de sociabilidades festivas, orientadas para a sociedade de acolhimento, em forma de uma arte que merece aplausos do público assistente. $\bigcirc$ que aproxima os jovens da Batoto Yetu não será apenas a memória das "raízes históricas" como, sobretudo, o caráter fusional da dança. Há um artigo de Schütz (1964) que realça este aspecto. $\bigcirc$ texto intitula-se "Making music together" e aparece em Collected Papers. Nesse texto, Schütz mostra-nos como a música favorece o partilhar de um "fluxo de consciência em relação aos outros", fluxo que é a base constitutiva de um "nós" que se sobrepõe a cada um de nós.

Em minhas primeiras observações etnográficas fiquei tocado pelo pulsar do que poderíamos designar de uma identidade étnica entre os jovens da Batoto Yetu. Depois descobri que sob o manto dessa aparente identidade existem outras realidades. Antes ou no intervalo de alguns ensaios, verifiquei que há jovens que dançam músicas de raiz não africana, quando colocam CDs, que trazem de casa, no aparelho de música. Entre os mais novos, notei uma especial adesão a registros musicais de telenovelas brasileiras. Assim sendo, o que parece uni-los, mais do que um essencialismo étnico, será o gosto lúdico pela dança. Ou seja, não é 
certo que a paixão pela dança corresponda, inevitavelmente, a uma tomada de consciência de marcas étnicas orientada por conquistas sociais e, muito menos, que os apegos étnicos se mantenham imunes aos fluíres sociais (Hechter, 1975). Ao se substituir a ideia de raça pela de cultura e ao opor-se a um determinismo "bio-racial" um determinismo "étnico cultural", por caminhos diferentes caímos num semelhante tipo de reducionismo (Chebel, 1998).

A diversidade cultural é historicamente evidente. No entanto, ela não se encerra em heranças históricas reificadas que colocam em causa a própria historicidade onde pululam e se reconstroem muitas outras diferenças (Back, 1993). Entre os jovens da Batoto Yetu constatei que o estereótipo da raça tem significados diferentes em diferentes contextos. A consciência da discriminação social exacerba o sentimento de comunhão étnica. Em outros contextos, porém, há uma propensão à partilha cultural. Por exemplo, é habitual, em algumas das suas exibições, os jovens da Batoto Yetu convidarem os assistentes a dançarem as suas músicas. Também verifiquei que o agogô que lhes ofereci foi incorporado como instrumento musical de suas performances. Aliás, a cultura de improvisação que caracteriza os grupos juvenis associados ao rap é de natureza compósita, e por isso utilizam a técnica do sampling. Em algumas composições musicais dos grupos do BJoy a própria música clássica é incorporada. A cultura da improvisação sugere-nos que há mais cultura para além da cultura etnicizada, tantas vezes reduzida a um caráter intrinsecamente normativo. A angariação de apoios financeiros para o projeto da Batoto Yetu - por exemplo, nas empresas - é feita com o envolvimento dos próprios jovens, tendo alguns deles a responsabilidade de escrever cartas ou participar em reuniões de negociação para o efeito. $\bigcirc$ envolvimento, embora residual, de jovens brancos no projeto é prova de que as manifestações culturais - mesmo que tenham uma raiz étnica - não são propriedade exclusiva de qualquer grupo étnico.

Quer-me parecer - mas é uma hipótese que deixo em aberto para futuras pesquisas - que o campo da educação é um campo de possibilidades - não aproveitadas - de fuga a esses determinismos reducionistas que amarram o cultural à sua negação, manifestada numa ausência de saberes compartilhados. A defesa do patrimônio cultural - que deveria ser olhado como um patrimônio coletivo - não tem sido equacionada como um desafio educativo. Apenas na última década do século $X X$, o patrimônio imaterial tem merecido algum reconhecimento por parte da Unesco e do Conselho da Europa. Recorde- 
se que a Convenção para a Salvaguarda do Patrimônio Cultural Imaterial da Unesco, embora aprovada em outubro de 2003, apenas entrou em vigor em abril de 2006 ${ }^{10}$; e a Convenção Quadro do Conselho da Europa relativa ao Valor do Patrimônio Cultural para a Sociedade, apenas foi assinada em outubro de 2005." Essa convenção lançou aos seus Estados-Membros o desafio de contemplarem a dimensão patrimonial cultural em todos os níveis de ensino, não necessariamente enquanto objeto de estudo específico mas como meio próprio de acesso a outros domínios do conhecimento. Pouco se avançou neste campo. Não obstante, quando questionados sobre as aprendizagens da história, os jovens europeus consideraram os museus e os lugares históricos como o rosto da história que mais satisfação e confiança lhes inspiravam; muito mais que os livros escolares, os documentários televisivos ou as narrativas dos professores (Pais, 1999, p.31-40).

É também importante interrogar os mecanismos da memória coletiva que permitem, através de diferentes processos de transmissão, conservar e vivificar as heranças do passado (Williams, I96I). Assim, se a arte tem sido considerada um dos domínios mais relevantes do patrimônio incorpóreo, há um abismo entre a forma como as "artes maiores" (arquitetura, escultura, pintura) têm sido consideradas e aquela como as "artes menores" (populares e artesanais) são desconsideradas. No entanto, embora as culturas populares tenham sido marginalizadas, a criatividade irrompe frequentemente nas margens da sociedade estabelecida, como tentamos mostrar neste artigo, ao percorrer algumas tradições musicais que, em Portugal e no Brasil, não por acaso partilham de um atributo comum - a improvisação - como também acontece, atualmente (estudo de caso analisado). Aos preconceitos que associam a cultura popular à frivolidade contrapuseram-se evidências da sua criatividade.

\section{REFERÊNCIAS BIBLIOGRÁFICAS}

ABREU, M. Histórias de cordéis e folhetos. Campinas: Mercado das Letras, 1999.

ALMEIDA, M. A. Memórias de um Sargento de Milícias. São Paulo: Ática, 1990.

10. Portugal ratificou a convenção em março de 2008.

I I. Em Portugal, a convenção viria a ser aprovada a 12 de setembro de 2008 (Resolução da Assembleia da República, I Série, n. 47/2008). 
ANTONACCI, M. A. Corpos sem fronteiras. Projeto História, São Paulo, n.25, p. I 45- I 80, dez. 2002.

BACK, L. New ethnicities and urban culture: racisms and multiculture in young lives. Londres: Universiy College, 1993.

BARRIGA, M. J. Cante ao baldão: uma prática de desafio no Alentejo. Lisboa: Colibri, 2003. BAUMANN, G. The Multicultutal riddle. Londres: Routledge, 1999.

BERMAN, M. Tudo o que é sólido se desmancha no ar: a aventura da modernidade. São Paulo: Companhia das Letras, 1986.

BEST, S.; KELLNER, D. Rap, revolta negra e diferença racial. Revista de Comunicação e Linguagem, Lisboa, n.30, p.201-224, 2001 .

BOIS-REYMOND, M. Learning between want and must: contradictions of the learning soociety. In: WALTHER, A.; STAUBER, B. (eds.) Lifelong learning in Europe: differences and divisions, 2. Tübingen: Neuling Veerlag, 1999. p.21-45.

BRANCO, M. B. Portugal e os estrangeiros. 2.ed. Lisboa: A. M. Pereira, 1879.

CASCUDO, L. da C. Dicionário do folclore. São Paulo: Ediouro, 1999.

CARVALHO, C. Eduardo ou os mistérios do limoeiro. Lisboa: Tipografia da Revolução de Setembro, 1849.

CHEBEL, A. Los Racismos cotidianos. Barcelona: Bellaterra, 1998.

FRADIQUE, T. Fixar o movimento: representações da música rap em Portugal. Lisboa: Dom Quixote, 2002.

FREYRE, G. Casa-grande \& senzala. 30.ed. Rio de Janeiro: Record, 1995.

GUSMÃO, N. M. M. Os Filhos de África em Portugal: antropologia, multiculturalismo e educação. Lisboa: Imprensa de Ciências Sociais, 2004.

HALL, S. Foreword in Claire Alexander. In: ALEXANDER, C. The Art of being black. Oxford: Oxford University Press, 2001 . p.5-7.

HALL, S. New ethnicities. In: DONALD, J.; RATTANSI, J. (eds.) Race, culture and difference. Londres: Sage, 1992. p.252-260.

HECHTER, M. Internal colonialism. London: Routledge, 1975.

HOBSBAWN, E.; RANGER, T. The Invention of tradition. Cambridge: Cambridge University Press, 1983. 
HOROWITZ, D. L. Ethnic groups in conflict. Berkeley: University of California Press, 1985. JAMES, W. Principles of psychology. 2.ed. Cambridge: Harvard University Press, 1988.

LANGE, F. C. A Organização musical durante o Período Colonial Brasileiro. In: COLÓQUIO INTERNACIONAL DE ESTUDOS LUSO-BRASILEIROS, 5. Actas... Coimbra: Universidade de Coimbra, 1996. v. 4, p.5-106.

LAPLANTINE, F. Do Rio de Janeiro a Lisboa, do fado dançado ao fado cantado: a questão das origens afro-brasileiras do fado. In: AMORIM. M. M.; ARAÚJO. N. (orgs.) Imaginário, cultura e mundo do trabalho: perspectivas contemporâneas. São Paulo: Terceira Margem, 2000. p.25-35.

MACHADO, F. L. Luso-africanos em Portugal: nas margens da etnicidade. Sociologia: Problemas e Práticas, n. 16, p. III-134, 1994.

MANGUEL, A. No Bosque do espelho. São Paulo: Companhia das Letras, 2000.

MORAES FILHO, J. A. M. Festas e tradições populares do Brasil. Belo Horizonte: Itatiaia, 1999.

MENDUS, S. Toleration and the limits of liberalism. London: Macmillan, 1989.

NENOCCHI, S. Viola chega ao rock sem perder raízes. O Estado de S. Paulo, v. I 8, n.5.952, p. I-3, 8 nov.2003. Caderno 2, capa.

MOTA, L. Cantadores. Ceará: Imprensa Universitária do Ceará, 1960.

NASCH, M. The Cauldron of ethnicity in the modern world. Chicago: University of Chicago Press, 1989.

ORNELLAS, M. Gaúchos e beduínos: a origem étnica e a formação social do Rio Grande do Sul. Martins: Porto Alegre, 1999.

OSTROWER, F. Universos de arte. Rio de Janeiro: Campus, 1983.

PAIS, J. M. Consciência história e identidade: os jovens portugueses num contexto europeu. Oeiras: Celta, 1999.

Porto: Âmbar, 2008.

A Prostituição e a Lisboa boémia do século XIX aos inícios do século XX, Vida cotidiana: enigmas e revelações. São Paulo: Cortez, 2003.

PIRES, R. P. Migrações e integração. Oeiras: Celta, 2003.

ROTHSCHILD, J. Ethnopolitics: a conceptual framework. New York: Columbia University Press, 1981. 
SARAIVA, A. Folhetos de cordel e outros da minha colecção. Porto: Biblioteca Municipal Almeida Garrett, 2006.

SCHAFER, M. O Ouvido pensante. São Paulo: Edunesp, 1992.

SCHÜTZ, A. Collected Papers, 2: Studies in social theory. The Hague: Nijhoff, I 964. p. I59178.

SIMMEL, G. Estudios psicológicos y etnológicos sobre música. Buenos Aires: Gorla, 2003.

TAGUIEFF, P. A. La Force du préjugé: essai sur le racisme et ses doubles. Paris: La Découverte, 1988.

TERRÉN, E. La Etnicidad y sus formas. Papers, n.66, p.45-57, 2002.

TINHORÃO, J. R. Os Sons dos negros no Brasil. São Paulo: Art, 1988.

VIANNA, H. O Mundo funk carioca. Rio de Janeiro: Jorge Zahar, 1988.

VILANOVA, V. C. A. O Axé e o sujeito do conhecimento. In: BIANCHI. A. (org.) Plantando axé: uma proposta pedagógica. São Paulo: Cortez, 2000. p.127-162

WILLIAMS, R. The Long revolution. Londres: Chatto and Windus, 1961.

Recebido em: junho 2009

Aprovado para publicação em: junho 2009 